\title{
SUPRESSÃO DA ATIVIDADE SAPROFÍTICA DE Rhizoctonia spp. EM SOLOS DE JARDIM CLONAL DE Eucalyptus*
}

\author{
EUGENIO A. SANFUENTES ${ }^{1}$, ACELINO C. ALFENAS ${ }^{2}$, LUIZ A. MAFFIA ${ }^{2}$, SILVALDO F. SILVEIRA $^{3}$, \\ RICARDO PENCHEL ${ }^{4} \&$ ROBERT C. SARTORIO ${ }^{4}$
}

'Departamento de Fitopatologia, Universidade Federal de Viçosa, 36571-000, Viçosa, MG, Brasil. Endereço atual: Departamento de Silvicultura, Facultad de Ciencias Forestales, Universidad de Concepción, Casilla 160-C, Concepción, Chile, e-mail: esanfuen@udec.cl, ${ }^{2}$ Departamento de Fitopatologia, Universidade Federal de Viçosa, 36571-000, Viçosa, MG, Brasil, ${ }^{3}$ Universidade Estadual do Norte Fluminense, 28015-620, Campos dos Goytacazes, Rio de Janeiro, Brasil, ${ }^{4}$ Aracruz Celulose S.A. Rd. Aracruz-Barra do Riacho, Km 25, 29197-000, Aracruz- ES, Brasil.

(Aceito para publicação em 24/07/2002)

Autor para correspondência: Eugenio A. Sanfuentes

SANFUENTES, E.A., ALFENAS, A.C., MAFFIA, L.A., SILVEIRA, S.F., PENCHEL, R. \& SARTORIO, R.C. Supressão da atividade saprofítica de Rhizoctonia spp. em solos de jardim clonal de Eucalyptus. Fitopatologia Brasileira 27:461467. 2002.

\section{RESUMO}

Avaliou-se a eficiência de Trichoderma longibranchiatum (UFV-1), de T. inhamatum (UFV-2 e UFV-3), compostos de casca e folhas de eucalipto contra Rhizoctonia spp., aplicados em solo de jardim clonal de eucalipto (Eucalyptus sp.). Em solos artificialmente infestados com Rhizoctonia spp., sob condições controladas, os antagonistas UFV-2 e UFV-3 apresentaram níveis elevados de supressividade, quando se aumentou a fonte alimentar na formulação, de 5 a $50 \mathrm{~g}$ de farelo de trigo por litro.
No campo, o antagonista UFV-3 não teve efeito significativo na redução do inóculo de Rhizoctonia spp. Compostos de casca de eucalipto apresentaram diferentes graus de supressão a Rhizoctonia spp., dependendo da origem e do lote do composto. A incorporação de folhas de eucalipto ao solo favoreceu o aumento do inóculo de Rhizoctonia spp.

Palavras-chave adicionais: controle biológico, patógenos de solo, doenças florestais.

\section{ABSTRACT \\ Suppression of Rhizoctonia spp. saprophytic activity in Eucalyptus clonal hedge soils}

The effectiveness of Trichoderma longibranchiatum (UFV-1), T. inhamatum (UFV-2 and UFV-3), eucalyptus bark compost and leaves of eucalyptus was tested for the suppression of Rhizoctonia spp. in the soil of a clonal hedge of eucalyptus under controlled conditions. Soils artificially infested with Rhizoctonia spp., the antagonists UFV-2 and UFV-3 showed high levels of suppression of the pathogen when the feeding formulation rose from 5 to $50 \mathrm{~g}$ wheat bran per liter. However, in the field, the antagonist UFV-3 did not show a significant effect in reducing the inoculum of Rhizoctonia spp. Eucalypt us bark compost resulted in different levels of suppression of the pathogen depending on the compost pile and source. Adding eucalyptus leaves to the soil favored the inoculum of Rhizoctonia spp.

\section{INTRODUÇÃO}

Mudas de eucalipto (Eucalyptus spp.) produzidas por estaquia em casa de vegetação são vulneráveis à incidência de fungos apodrecedores durante o enraizamento, mormente espécies do gênero Rhizoctonia De Candolle. Brotações infetadas, substratos infestados, bandejas e tubetes contaminados podem constituir fontes de inóculo a estacas nesta fase (Alfenas et al., 1997). Silveira et al. (2000) observaram que Rhizoctonia solani Kühn AG1-1B, seguido por isolados binucleados de Rhizoctonia spp., predominaram como agentes etiológicos nas amostragens conduzidas em diferentes localidades no Brasil.

\footnotetext{
* Parte da Tese de Doutorado do primeiro autor. Universidade Federal de Viçosa (2000)
}

As medidas de controle da doença têm sido tradicionalmente direcionadas à erradicação do inóculo do patógeno dentro da casa de vegetação. Dentre estas, a mais importante é o uso de brotações sadias, de modo a evitar o ingresso do patógeno a partir de brotações contaminadas. A seleção e a imersão das estacas em caldas fungicidas, sob altos níveis de doença no jardim clonal, são ineficientes quando aplicadas isoladamente. $\mathrm{O}$ desenvolvimento posterior da doença não tem sido estudado, mas acredita-se que a dispersão do patógeno, entre estacas na casa de vegetação, pode ser extremamente rápida e depende de vários fatores, como quantidade do inóculo e agressividade do isolado, condições de higiene e natureza do substrato, o que dificulta o controle da doença.

A incorporação de Trichoderma spp. Pers ex Fr em composto de casca de eucalipto, sob condições controladas, 


\section{E.A. Sanfuentes et al.}

apresenta diferentes graus de eficiência no controle da mela de estacas (Kunieeda-de-Alonso, 1997). Entretanto, ela não elimina o inóculo inicial proveniente das brotações infestadas, nem tampouco a disseminação aérea de uma estaca para outra nas bandejas. A redução do inóculo de Rhizoctonia spp. no solo de jardim clonal, pelo uso de antagonistas ou pela incorporação de matéria orgânica ao solo, pode se constituir em estratégia viável de controle, no contexto de manejo integrado da doença. Trabalhos de controle biológico de Rhizoctonia spp. em solos naturais têm sido desenvolvidos, em sua maioria, sob condições controladas (Lewis \& Papavizas, 1987; Knudsen \& Bin, 1990; Lewis et al., 1991, 1996). Há relatos de eficiência do controle biológico sob condições de campo em outros patossistemas (Elad et al., 1980; Huang \& Kulhman, 1991; Yuen et al., 1994; Ross et al., 1998).

Neste trabalho, estudaram-se os efeitos da incorporação no solo de jardim clonal de isolados de antagonistas e de compostos de casca e folhas de eucalipto, visando à supressão de Rhizoctonia spp., provavelmente constituindo-se na primeira tentativa de implementar, no campo, o controle biológico no patossistema Rhizoctonia spp.- eucalipto.

\section{MATERIAL E MÉTODOS}

Avaliou-se a capacidade supressiva a Rhizoctonia spp. de três isolados de Trichoderma, UFV-1 (Trichoderma longibranchiatum Rifai), UFV-2 e UFV-3 (Trichoderma inhamatum Veerkamp \& W. Gams), formulados em "pellets" de alginato de sódio, e de resíduos de peneiramento de composto de casca de eucalipto e restos de folhas de eucalipto. Os compostos de casca testados, predominantemente de Eucalyptus grandis Hill Ex. Maiden, foram cedidos pelas empresas Aracruz Celulose - AR (Aracruz - ES), Bahia Sul Celulose - BSC (Teixeira de Freitas - BA) e Cenibra Florestal - CF (Belo Oriente - MG). Os compostos de casca consistiram de resíduos de maior granulometria, resultantes do peneiramento na elaboração de substrato de enraizamento. As amostras testadas de cada composto foram homogeneizadas em peneiras de $3 \mathrm{~cm}$ de malha e com teor de umidade variando de 60 a $75 \%$. As folhas de eucalipto usadas, predominantemente de E. grandis, resultantes do descarte do preparo de estacas na Aracruz Celulose, encontravam-se parcialmente decompostas.

\section{Produção massal e formulação dos antagonistas}

Os isolados de Trichoderma spp. foram anteriormente pré-selecionados quanto à capacidade supressiva a Rhizoctonia spp. (Kunieeda-de-Alonso, 1997). Para a produção massal, discos de cultivo em BDA (Batata-DextroseÁgar) foram repicados para Erlenmeyers de $1.000 \mathrm{ml}$ de capacidade, contendo $500 \mathrm{ml}$ de meio líquido de batatadextrose (BD), seguindo-se incubação a $28^{\circ} \mathrm{C} \pm 2$, sob agitação rotativa, a $120 \mathrm{rpm}$. A massa micelial, contendo micélio e clamidosporos, foi coletada e lavada três vezes em água destilada esterilizada, sob vácuo (bomba DIA-PUMP ${ }^{\circledR}$,
FANEM, Brasil). Após remover o excesso de água por prensagem em papel-filtro, a massa micelial foi armazenada a $4{ }^{\circ} \mathrm{C}$, por no máximo $48 \mathrm{~h}$, antes de seu uso. Os antagonistas foram encapsulados em "pellets" de alginato de sódio segundo metodologia descrita por Lewis \& Papavizas (1987), contendo farelo de trigo como fonte alimentar, cuja concentração variou de 5 a $50 \mathrm{~g} / 1$. Os "pellets" foram armazenados a $4{ }^{\circ} \mathrm{C}$, por no máximo 45 dias, até o uso. Em cada ensaio, uma amostra de 60 "pellets" foi semeada em meio BDA ( $\mathrm{pH} \mathrm{5,0),} \mathrm{para}$ determinar a viabilidade dos antagonistas e comprovar a inexistência de contaminantes fúngicos ou bacterianos.

\section{Produção de inóculo do patógeno e infestação do solo}

Empregou-se a cultura RH-18 de Rhizoctonia solani Kühn (AG1-1B), isolada de folhas de eucalipto com sintomas de queima foliar, coletadas em jardim clonal. Para a infestação do solo, seguiram-se os métodos de Ko \& Hora (1971) e de Sneh et al. (1991). O inóculo foi armazenado à temperatura ambiente, por no máximo sete dias e, antes de cada ensaio, o inóculo foi semeado em meio de ágar-água (2\%), $\mathrm{pH} 5,0$, para avaliar sua viabilidade e a isenção de contaminantes.

\section{Ensaios sob condições controladas}

Realizaram-se dois ensaios, utilizando amostras de solo coletadas nos jardins clonais da Aracruz Celulose (Aracruz ES) e Cenibra Florestal (Belo Oriente - MG), denominadas $\mathrm{AR}$ e $\mathrm{CF}$, respectivamente. Os solos foram coletados à profundidade máxima de $7 \mathrm{~cm}$, peneirados a $4 \mathrm{~mm}$, secos ao ar e armazenados à temperatura ambiente $\left(24-26^{\circ} \mathrm{C}\right)$ por até dois meses antes do uso. As amostras de solos apresentaram as seguintes características: solo AR com textura francoarenosa $(60 \%$ de areia grossa, $18 \%$ de areia fina, $6 \%$ de silte e $16 \%$ de argila), pH 5,0, matéria orgânica (MO) de 4,62 $\mathrm{dag} / \mathrm{kg}$ e capacidade de campo (CC) de 14,6\% (-0,1 bar); solo CF com textura franco-argilo-arenosa $(56 \%$ de areia grossa, $11 \%$ de areia fina, $11 \%$ de silte e $16 \%$ de argila), $\mathrm{pH}$ 4,7, MO 2,69 dag/kg e CC de 18,6\% (-0,3 bar). Antes de cada ensaio, verificou-se a presença de inóculo de Rhizoctonia spp. em cada solo, pelo método de peneiramento úmido, conforme descrito por Weinhold (1977). Os antagonistas foram incorporados no solo a $2 \%$ peso/volume; e o composto de casca e folhas de eucalipto, a 33\% volume/volume. Avaliouse, semanalmente, até um máximo de quatro semanas, a densidade de inóculo de Rhizoctonia spp., utilizando-se o método de colonização de iscas de eucalipto (Sanfuentes \& Alfenas, 1998). A umidade foi ajustada entre 70 e 100\% da CC. Os ensaios foram realizados em câmaras de crescimento climatizadas, a $26 \pm 2{ }^{\circ} \mathrm{C}$, fotoperíodo de $12 \mathrm{~h}$ e intensidade luminosa variando entre 3.800 e 4.800 Lux. O delineamento foi inteiramente casualizado, com três repetições de 30 iscas cada, por época e tratamento. Para análise dos resultados, em cada época de avaliação, utilizou-se o teste de Tukey $(\mathrm{p}=0,05)$, e, quando necessário, as médias foram transformadas por $\operatorname{arcsen}(\mathrm{X})^{1 / 2}$. A seguir, descrevem-se condições específicas ou modificações realizadas para cada ensaio. 
Ensaio 1: Empregou-se o solo AR, infestado com Rhizoctonia spp., conforme metodologia de Ko \& Hora (1971). Os antagonistas foram formulados conforme descrito no item de produção massal e formulação, utilizando-se $5 \mathrm{~g}$ de farelo de trigo por litro como fonte alimentar. O composto de casca AR e as folhas de eucalipto foram coletados em setembro de 1997 (lote 1).

Ensaio 2: Empregaram-se os solos AR e CF, artificialmente infestados com Rhizoctonia spp. cultivado em grãos de sorgo, conforme metodologia de Sneh et al. (1991). Os antagonistas foram formulados com $50 \mathrm{~g}$ de farelo de trigo por litro como fonte alimentar. Foram testados os compostos de casca AR e folhas de eucalipto, coletados em novembro de 1998 (lote 2), e os compostos BSC e CF.

\section{Supressão de Rhizoctonia spp. em microparcelas no jardim clonal}

Os ensaios 3 e 4 foram realizados em jardins clonais de eucalipto da Aracruz Celulose (Aracruz - ES) e Cenibra Florestal (Belo Oriente - MG), respectivamente. As características dos solos foram descritas previamente. As microparcelas foram constituídas por tubos circulares de PVC, de $19,5 \mathrm{~cm}$ de diâmetro e $15 \mathrm{~cm}$ de altura, enterrados no solo à profundidade de $10 \mathrm{~cm}$. As microparcelas foram instaladas paralelamente às linhas de plantio, a aproximadamente 15 $\mathrm{cm}$ das cepas e espaçadas $5 \mathrm{~cm}$ entre si. $\mathrm{Na}$ instalação do ensaio, retirou-se uma amostra de 600-700 g de solo, para determinar a densidade de inóculo de Rhizoctonia spp. e, após 32 dias, avaliou-se a densidade de inóculo do fungo em cada tratamento, empregando-se em ambos os casos o método de colonização de iscas de eucalipto (Sanfuentes \& Alfenas, 1998). No ensaio em Belo Oriente, adicionalmente infestouse o solo com $R$. solani AG1 (2 g de sorgo/microparcela), conforme Sneh et al. (1991), equivalente a 90\% de colonização de iscas de eucalipto.

$\mathrm{O}$ antagonista (UFV-3) e os compostos de casca e folhas de eucalipto foram incorporados ao solo na mesma proporção utilizada nos ensaios de supressão sob condições controladas. Nos ensaios, incluiu-se um tratamento que consistiu do composto AR esterilizado, o qual foi autoclavado a $121{ }^{\circ} \mathrm{C}$ por $1 \mathrm{~h}$, em dois dias, com um dia de intervalo. Adicionalmente, no jardim da Aracruz Celulose, incluiu-se um tratamento constituído da mistura do composto de casca de eucalipto (AR) e folhas $(1: 1)$, incorporado no solo a $33 \%$ volume/volume. No ensaio em Belo Oriente, incluiu-se outro tratamento, contendo a mistura de composto de casca de eucalipto (AR) $(33 \% \mathrm{v} / \mathrm{v})$ e antagonista $(1 \% \mathrm{p} / \mathrm{v})$, previamente incubada por $48 \mathrm{~h}$, antes da incorporação no solo.

Para avaliar as variações de temperatura e umidade do solo, foram instalados dois tubos de PVC por tratamento, analogamente ao descrito anteriormente para os tratamentos. Aferiu-se diariamente a temperatura do solo, a $3 \mathrm{~cm}$ de profundidade às 9 e $13 \mathrm{~h}$ e às 9 e $15 \mathrm{~h}$, em Aracruz e Belo Oriente, respectivamente. Coletaram-se amostras de solo, a cada três dias, entre 0 e $6 \mathrm{~cm}$ de profundidade, para se determinar a umidade $(\% \mathrm{p} / \mathrm{p})$ pelo método gravimétrico. Em Belo Oriente, a irrigação foi por aspersão, enquanto em Aracruz foi por gotejamento, na base de cada cepa. Os ensaios foram delineados em cinco blocos casualizados, distribuídos no campo, nos setores com maiores níveis de infestação de Rhizoctonia spp., determinados previamente. Para análise dos resultados, empregaram-se a análise de covariância e dados entre as médias dos tratamentos, mediante o uso do programa SAS. Nas análises de covariância, a densidade de inóculo de Rhizoctonia spp. de cada tratamento (Y) foi corrigida pela covariável $(\mathrm{X})$, segundo o modelo $\mathrm{Y}_{\mathrm{i}}=\mathrm{Y}_{\mathrm{i}}-\mathrm{b}\left(\mathrm{X}_{\mathrm{i}}\right.$ $\mathrm{X}$ ), sendo $\mathrm{Y}$ a densidade final do tratamento (i) aos 32 dias, $\mathrm{X}_{\mathrm{i}}$ a densidade inicial do tratamento (i), $\mathrm{X}$ a densidade média inicial dos tratamentos e "b" a inclinação da equação de regressão.

\section{RESULTADOS}

Supressão de Rhizoctonia spp. em condições controladas

No ensaio 1, o composto de casca de eucalipto (AR) destacou-se na redução da densidade de inóculo de Rhizoctonia spp., com os menores valores de colonização em todas as épocas de avaliação, as quais diferiram significativamente dos demais tratamentos aos 14 e 21 dias (Tabela 1). Com a incorporação de folhas de eucalipto no solo, o fungo manteve a densidade de inóculo em níveis similares aos do tratamento testemunha. Os antagonistas UFV-1 e UFV-2 apresentaram efeito supressivo nas primeiras semanas, mas com altos níveis de atividade do fungo, quando comparados ao composto de casca, e não diferiram da testemunha, ao final do período experimental. $\mathrm{O}$ antagonista UFV-3 teve um efeito supressivo semelhante a UFV-1 e UFV-2, durante as três primeiras semanas, entretanto aos 28 dias foi superior a estes, e sem diferenças significativas com o composto AR (Tabela 1).

No ensaio 2, os antagonistas reduziram significativamente a densidade de inóculo de Rhizoctonia spp., a partir

TABELA 1 - Percentagem de colonização de iscas de eucalipto (Eucalyptus spp.) por Rhizoctonia spp. em função de antagonistas, e compostos de casca de folhas de eucalipto, no solo AR (Aracruz - ES) artificialmente infestado com Rhizoctonia solani (ensaio 1)

\begin{tabular}{lcccc}
\hline \hline \multirow{2}{*}{ Tratamento } & \multicolumn{4}{c}{ Colonização de iscas por } \\
& \multicolumn{4}{c}{ Rhizoctonia spp. (\%) } \\
\cline { 2 - 5 } & $\mathbf{7}$ dias & 14 dias & 21 dias & $\mathbf{2 8}$ dias \\
\hline Testemunha & $97,8 \mathrm{a}^{1}$ & $91,1 \mathrm{a}$ & $88,9 \mathrm{a}$ & $61,1 \mathrm{a}$ \\
$\begin{array}{l}\text { Trichoderma } \\
\quad \text { longibranchiatum UFV-1 }\end{array}$ & $76,7 \mathrm{~b}$ & $87,8 \mathrm{a}$ & $73,3 \mathrm{ab}$ & $61,1 \mathrm{a}$ \\
T. inhamatum UFV-2 & $60,0 \mathrm{c}$ & $53,3 \mathrm{~b}$ & $64,4 \mathrm{~b}$ & $63,3 \mathrm{a}$ \\
T. inhamatum UFV-3 & $66,7 \mathrm{bc}$ & $41,1 \mathrm{~b}$ & $53,3 \mathrm{~b}$ & $36,7 \mathrm{bc}$ \\
Folhas & $96,7 \mathrm{a}$ & $95,6 \mathrm{a}$ & $70,6 \mathrm{ab}$ & $52,2 \mathrm{ab}$ \\
Composto AR (lote 1) & $58,9 \mathrm{c}$ & $23,3 \mathrm{c}$ & $24,4 \mathrm{c}$ & $16,7 \mathrm{c}$ \\
\hline
\end{tabular}

(1) Em cada coluna, as médias seguidas pela mesma letra, no sentido vertical, não diferem significativamente entre si, pelo teste de Tukey $(\mathrm{p} \leq 0,05)$. 


\section{E.A. Sanfuentes et al.}

da segunda semana no solo AR e da primeira semana no solo CF (Tabela 2). Em ambos os solos, verificou-se redução contínua do inóculo de Rhizoctonia spp., acentuando-se a partir da terceira semana e, no solo AR, os antagonistas UFV2 e UFV-3 eliminaram completamente o inóculo de Rhizoctonia spp. Os compostos AR, BSC e CF mantiveram alta densidade de inóculo de Rhizoctonia spp.; entretanto, com as folhas de eucalipto, verificou-se aumento da densidade de inóculo (Tabela 2). Na testemunha, em que se utilizou o solo CF, a população de Rhizoctonia spp. reduziu-se drasticamente na última semana de avaliação.

\section{Supressão de Rhizoctonia spp. em microparcelas no jardim clonal}

Detectaram-se diferenças significativas entre os tratamentos em ambos os solos testados (Tabela 3). No ensaio da Aracruz, a incorporação de casca de eucalipto AR foi o único tratamento que reduziu significativamente $(\mathrm{p}<0,10)$ a densidade de inóculo de Rhizoctonia spp. após 32 dias de duração do ensaio (Tabelas 3 e 4). Não foram detectadas diferenças significativas quanto aos efeitos do composto AR, natural ou estéril, bem como na incorporação conjunta com o antagonista UFV-3. Entretanto, as folhas e o composto BSC aumentaram significativamente a densidade de inóculo de Rhizoctonia spp. Nos tratamentos constituídos por composto e folhas, a umidade manteve-se sempre mais alta que no solo não-tratado (registro não apresentado). Assim, em mais de 50 a $80 \%$ das datas em que se realizaram as amostragens, a umidade foi maior que $50 \%$ da capacidade de campo, para o composto e folhas de eucalipto, enquanto no solo não-tratado a umidade foi inferior a $30 \%$. As temperaturas médias do solo foram semelhantes entre os tratamentos, sendo de 30,5 ${ }^{\circ} \mathrm{C}, 29,5{ }^{\circ} \mathrm{C}$ e $31,3{ }^{\circ} \mathrm{C}(9: 00 \mathrm{AM})$ e, $38,0{ }^{\circ} \mathrm{C}, 38,4{ }^{\circ} \mathrm{C}$ e $39,0{ }^{\circ} \mathrm{C}$ (1:00 PM), para os tratamentos com composto, folha e solo desnudo, respectivamente.

No ensaio em Belo Oriente, compostos de casca de eucalipto (AR, CF e BSC) e antagonista (UFV-3) não reduziram a densidade de inóculo de Rhizoctonia spp. (Tabela 3 e 4). Com a incorporação do antagonista, verificou-se menor densidade de inóculo que nos tratamentos com a casca de eucalipto ou na testemunha, embora o efeito não tenha sido significativo. A redução da atividade de Rhizoctonia spp. no solo natural (testemunha) foi comum para ambos os ensaios. A incorporação do composto de casca AR+antagonista (UFV3) não aumentou significativamente o efeito do composto aplicado individualmente. Todavia, verificou-se que o composto natural (AR) diferiu significativamente do composto autoclavado e, neste último, houve aumento significativo da atividade de Rhizoctonia spp., analogamente ao efeito da incorporação de folhas no solo (Tabela 4). Neste jardim clonal, a umidade permaneceu alta durante todo o período do ensaio, acima de $125 \%$ da $\mathrm{CC}$, inclusive com valores maiores nos tratamentos com casca e folhas. A freqüente irrigação permitiu manter esses altos níveis de umidade do solo. As temperaturas médias do solo foram semelhantes entre os tratamentos: $20 \pm$ $1,5{ }^{\circ} \mathrm{C}\left(9: 00\right.$ AM) e $26,5 \pm 1,5{ }^{\circ} \mathrm{C}(3: 00 \mathrm{PM})$.

\section{DISCUSSÃO}

Os resultados demonstraram a eficiência dos antagonistas T. inhamatum (UFV-2 e UFV-3) e T. longibranchiatum (UFV-1) na redução da densidade de inóculo de Rhizoctonia spp., em condições controladas. Esses resultados foram similares aos obtidos por Lewis \& Papavizas (1987) e Lewis et al. (1991), na supressão de $R$. solani por Trichoderma harzianum Rifai, T. viride Pers.: Fr. e Gliocladium virens Miller, Gidden \& Foster. Todavia, no presente trabalho, constatou-se ampla variação nos níveis de supressividade. As diferenças entre os ensaios em condições controladas foram associadas principalmente ao aumento na concentração da fonte alimentar nos antagonistas peletizados. No ensaio 1, com $5 \mathrm{~g}$ de farelo de trigo por litro, nas primeiras semanas os antagonistas reduziram significativamente a atividade saprofítica de Rhizoctonia spp., mas o efeito supressivo

TABELA 2 - Percentagem de colonização de iscas de eucalipto (Eucalyptus spp.) por Rhizoctonia spp., em função de antagonistas e compostos de casca, no solos AR (Aracruz - ES) e CF (Belo Oriente - MG), artificialmente infestados com Rhizoctonia solani (ensaio 2)

\begin{tabular}{|c|c|c|c|c|c|c|c|c|}
\hline \multirow{3}{*}{ Tratamento } & \multicolumn{8}{|c|}{ Colonização de iscas por Rhizoctonia spp. (\%) } \\
\hline & \multicolumn{4}{|c|}{ Solo AR ${ }^{1}$} & \multicolumn{4}{|c|}{ Solo $\mathbf{C F}^{2}$} \\
\hline & 7 dias & 14 dias & 21 dias & 28 dias & 7 dias (1) & 14 dias (1) & 21 dias (2) & 28 dias (2) \\
\hline Testemunha & $96,7 \mathrm{ab}^{3}$ & $100,0 \mathrm{a}^{3}$ & $82,2 \mathrm{a}^{3}$ & $82,2 \mathrm{a}^{3}$ & $98,9 \mathrm{a}^{3}$ & $95,6 \mathrm{a}^{3}$ & $78,9 \mathrm{a}^{3}$ & $31,1 \mathrm{~b} \mathrm{c}^{3}$ \\
\hline Trichoderma longibranchiatum UFV-1 & $86,7 \mathrm{ab}$ & $52,2 \mathrm{~b}$ & $7,8 \mathrm{~b}$ & $7,8 \mathrm{~b}$ & 82,2 bc & $58,9 \mathrm{~b}$ & $3,3 \mathrm{~b}$ & $7,8 \mathrm{~cd}$ \\
\hline T. inhamatum UFV-2 & $72,2 \mathrm{~b}$ & $14,4 \mathrm{c}$ & $3,3 \mathrm{~b}$ & $0,0 \mathrm{~b}$ & $67,8 \mathrm{c}$ & $12,2 \mathrm{c}$ & $10,0 \mathrm{~b}$ & $4,4 \mathrm{~d}$ \\
\hline T. inhamatum UFV-3 & $8,9 \mathrm{c}$ & $18,2 \mathrm{c}$ & $2,2 \mathrm{~b}$ & $0,0 \mathrm{~b}$ & $24,4 \mathrm{~d}$ & $20,0 \mathrm{c}$ & $4,4 \mathrm{~b}$ & $1,5 \mathrm{~d}$ \\
\hline Composto AR (lote 2) & 98,9 a & $100,0 \mathrm{a}$ & 88,9 a & $65,2 \mathrm{a}$ & $97,8 \mathrm{ab}$ & $94,4 \mathrm{a}$ & $80,0 \mathrm{a}$ & $55,3 \mathrm{ab}$ \\
\hline Composto BSC & $98,9 \mathrm{a}$ & 98,9 a & $100,0 \mathrm{a}$ & $76,7 \mathrm{a}$ & $94,4 \mathrm{ab}$ & $100,0 \mathrm{a}$ & $86,7 \mathrm{a}$ & $60,0 \mathrm{ab}$ \\
\hline Composto CF & $100,0 \mathrm{a}$ & $100,0 \mathrm{a}$ & $73,3 \mathrm{a}$ & 86,6 a & 98,9 a & $100,0 \mathrm{a}$ & 84,4 a & $84,4 \mathrm{ab}$ \\
\hline Folhas & $100,0 \mathrm{a}$ & $100,0 \mathrm{a}$ & 98,9 a & $100,0 \mathrm{a}$ & $100,0 \mathrm{a}$ & $100,0 \mathrm{a}$ & $100,0 \mathrm{a}$ & $100,0 \mathrm{a}$ \\
\hline
\end{tabular}

(1) Para análise de variância, os dados foram transformados por arcsen $\left[(\mathrm{x} / 100)^{1 / 2}\right]$.

(2) Para análise de variância, os dados foram transformados por $(x+0,5)^{1 / 2}$.

(3) Médias seguidas pela mesma letra, no sentido vertical, não diferem entre si, pelo teste de Tukey $(\mathrm{p}=0,05)$. 
TABELA 3 - Densidades inicial (DI) e final (DF) de inóculo de Rhizoctonia spp., expressas como percentagem de colonização de iscas de eucalipto (Eucalyptus spp.), após a aplicação de antagonistas e compostos de casca e folhas de eucalipto, nos ensaios realizados no jardim clonal de Aracruz Celulose (Aracruz - ES) e Cenibra Florestal (Belo Oriente - MG)

\begin{tabular}{|c|c|c|c|c|}
\hline \multirow[t]{2}{*}{ Tratamento } & \multicolumn{2}{|c|}{$\begin{array}{l}\text { Aracruz } \\
\text { Celulose }\end{array}$} & \multicolumn{2}{|c|}{$\begin{array}{c}\text { Cenibra } \\
\text { Florestal }\end{array}$} \\
\hline & DI & DF & DI & DF \\
\hline Testemunha & 34,32 & 16,98 & 47,24 & 18,85 \\
\hline Trichoderma. inhamatum UFV-3 & 25,66 & 16,57 & 34,40 & 9,72 \\
\hline Composto $\mathrm{AR}^{(1)(4)}$ & 29,34 & 4,95 & 43,14 & 26,58 \\
\hline Composto $\mathrm{AR}^{(2)}$ & 40,68 & 7,34 & 42,46 & 50,97 \\
\hline Composto AR+UFV-3 & 34,00 & 6,74 & 42,12 & 21,41 \\
\hline Composto BSC $^{(5)}$ & 25,40 & 18,98 & 45,86 & 26,42 \\
\hline Composto $\mathrm{CF}^{(6)}$ & $\mathrm{NR}^{(3)}$ & NR & 48,00 & 21,49 \\
\hline Folhas & 40,32 & 24,77 & 54,66 & 76,38 \\
\hline Composto AR+Folhas & 34,32 & 33,99 & NR & NR \\
\hline
\end{tabular}

(1) composto natural; (2) composto autoclavado; (3) tratamento não-realizado; (4) composto AR (Aracruz - Celulose); (5) composto BSC (Teixeira de Freitas - BA); (6) composto CF (Belo Oriente-MG)

diminuiu gradualmente até 28 dias. Entretanto, no ensaio 2 a utilização de $50 \mathrm{~g}$ de farelo de trigo por litro reduziu a atividade saprofítica de Rhizoctonia spp., em níveis que não permitiram sua detecção.

A importância de se utilizar uma fonte alimentar nas formulações de antagonistas, para o controle de patógenos em solos naturais, já foi observada em outros estudos. Assim, obtiveram-se diferenças significativas na redução da atividade saprofítica e sobrevivência de $R$. solani, ao se incorporar farelo de trigo em doses crescentes na formulação, reduzindo de $78 \%$ para $9 \%$ com T. inhamatum e de $68 \%$ para $20 \%$ com $T$. virens (Miller, Giddens \& Foster) von Arx, associado ao aumento de 30 a 40 vezes da população desses antagonistas (Lewis \& Papavizas, 1987). Analogamente, a eficiência de $T$. harzianum no controle de $R$. solani e de Sclerotium rolsfii Sacc. correlacionou-se positivamente com o aumento da quantidade de farelo de trigo aplicado no solo e negativamente com o aumento da população do patógeno, explicado pelo aumento significativo da biomassa de hifas do antagonista, demonstrando o efeito positivo na proliferação do agente de biocontrole (Elad et al., 1980).

Nos ensaios, realizados em microparcelas no campo, T. inhamatum (UFV-3) não reduziu a população de Rhizoctonia spp., contrastando com os resultados obtidos em condições controladas. Em Aracruz, as condições de umidade de solo, permanentemente abaixo de $50 \% \mathrm{CC}$, e as altas temperaturas superficiais, $36-38{ }^{\circ} \mathrm{C}$, podem ter sido determinantes na ineficiência do antagonista. Temperaturas de $37{ }^{\circ} \mathrm{C}$ e umidade de solo menores que -1 bar reduziram consistentemente o nível de colonização saprofítica de $T$. harzianum (Eastburn \& Butler, 1991). Há grande amplitude nas condições ecológicas que determinaram a dinâmica de cada espécie de Trichoderma no solo. Em geral, em solos secos por prolongados períodos de tempo, ocorre redução das populações de Trichoderma e Gliocladium (Danielson e Davet, 1973, citados por Papavizas, 1985). Em Belo Oriente, a umidade do solo foi sempre maior que $125 \%$ da CC, com temperaturas máximas de solo entre 25 e $26{ }^{\circ} \mathrm{C}$. Nessas condições, apesar de haver maior colonização de Trichoderma spp. nas iscas de eucalipto, não houve efeito significativo na redução de Rhizoctonia spp., quando comparada com a ocorrida na testemunha.

Os compostos à base de casca de eucalipto apresentaram resultados de supressão que variaram em função da origem e do lote do composto. No ensaio $1 \mathrm{e}$ em outros ensaios realizados (dados não apresentados), com o composto $\mathrm{AR}$ (lote 1), os níveis de supressão de Rhizoctonia spp. variaram entre 71,8 e $90 \%$. Entretanto, no segundo ensaio, utilizando o lote 2, não se verificou qualquer efeito supressivo. Os compostos de casca BSC e CF não foram supressivos a Rhizoctonia spp., em todos os ensaios realizados. O efeito de supressão com o uso de compostos de casca tem sido explicado fundamentalmente pelo incremento da atividade antagônica de microrganismos no solo ou nos substratos, especialmente por espécies de Trichoderma e Gliocladium (Kwok et al., 1987; Kuter et al., 1988; Chung et al., 1988; Tuiter et al.,

TABELA 4 - Análise de contrastes entre médias de tratamentos, quanto à percentagem de iscas colonizadas por Rhizoctonia spp., obtidas pela análise de covariância, no ensaio de microparcelas realizado no jardim clonal da Aracruz Celulose (Aracruz - ES) e da Cenibra Florestal (Belo Oriente - MG) (ensaios 3 e 4)

\begin{tabular}{|c|c|c|c|c|c|c|}
\hline \multirow{2}{*}{ Contraste } & \multicolumn{3}{|c|}{ Aracruz - ES } & \multicolumn{3}{|c|}{ Belo Oriente - MG } \\
\hline & QM & $\mathbf{F}$ & $\mathbf{p}>\mathbf{F}$ & QM & $\mathbf{F}$ & $\mathbf{p}>\mathbf{F}$ \\
\hline 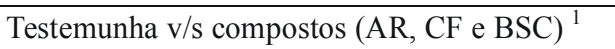 & 161,14 & 1,50 & 0,2316 & 742,5 & 2,21 & 0,1484 \\
\hline Testemunha v/s compostos $\mathrm{AR}^{2}$ & 390,65 & 3,63 & 0,0674 & 1271,19 & 3,79 & 0.0620 \\
\hline Testemuna v/s Trichoderma inhamatum UFV-3 & - & - & - & 162,18 & 0,48 & 0,4928 \\
\hline Composto AR natural v/s autoclavado & 14,36 & 0,13 & 0,7177 & 1480.86 & 4,42 & 0,0451 \\
\hline Composto AR v/s composto BSC & 528,09 & 4,91 & 0,0353 & - & - & - \\
\hline Composto AR v/s composto AR+UFV3 & 1,15 & 0,01 & 0,9183 & 68,16 & 0,20 & 0,6557 \\
\hline Testemunha $\mathrm{v} / \mathrm{s}$ folhas & 511,91 & 4,76 & 0,0380 & 7564,14 & 22,55 & 0,0001 \\
\hline
\end{tabular}

(1)Composto AR (Aracruz - ES), CF (Belo Oriente - MG) e BSC (Teixeira de Freitas - BA).

(2)Inclui compostos, natural e autoclavado 
1988; Hardy \& Sivasithamparam, 1995).

Em Aracruz, o composto de casca AR reduziu significativamente a atividade saprofítica de Rhizoctonia spp., enquanto em Belo Oriente não houve qualquer efeito. Esses resultados coincidem com o encontrado nos ensaios em condições controladas, quanto ao efeito supressivo de compostos de mesmo lote. A densidade de inóculo de Rhizoctonia spp. pode ter sido mantida por nutrientes do próprio composto, capazes de suportar altos níveis de colonização deste fungo. A natureza conduciva de um composto fresco pode ser resultado, em parte, da habilidade de Rhizoctonia spp. em incrementar a sua densidade de inóculo, pela utilização da celulose. Entretanto, a utilização de celulose por Rhizoctonia spp. dependerá da microbiota residente no solo e de sua acessibilidade à celulose, que pode ser influenciada pelo conteúdo de lignina da casca (Tuiter et al., 1988). Por outro lado, um alto conteúdo de celulose resulta em acúmulo de glicose, o que reprime a produção de quitinase, inibindo conseqüentemente o hiperparasitismo de Trichoderma (Chung et al., 1988). Nos presentes ensaios, não se determinou a quantidade de celulose e de outros componentes nos compostos de casca estudados. Todavia, provavelmente, a quantidade de celulose disponível foi elevada, considerando-se o tipo de compostagem parcial, quatro meses, somado ao alto conteúdo de holocelulose (72$62 \%$ ) presente na casca fresca de eucalipto (Andrade, 1989). A compostagem realizada nas empresas florestais visa obter um substrato com características físicas, como granulometria e porosidade, apropriadas para enraizamento, sem considerar suas características biológicas. Possivelmente, os resíduos da compostagem, que haviam sido descartados por tamanho, aumentaram a possibilidade de se estar usando um material com menor grau de decomposição e com maiores teores de celulose.

A incorporação do antagonista ao composto de casca AR não aumentou a eficiência em reduzir a densidade de inóculo de Rhizoctonia spp. Entretanto, no solo CF, o antagonista reduziu parcialmente a densidade de inóculo do fungo, mas sem apresentar diferenças com o solo não-tratado. Provavelmente, o período de pré-incubação não foi suficiente para promover colonização satisfatória do antagonista, a qual foi reduzida quando o composto foi aplicado ao solo, como resultado da competição pela microbiota do solo. Foram necessários no mínimo sete dias de pré-incubação de $T$. harzianum e G. virens em um composto de casca de Pinus sp., para haver níveis de controle adequados contra Pythium ultimum Trow e $R$. solani (Steinnmetz \& Schönbeck, 1994). Por outro lado, foram necessários 60 dias de pré-incubação dos antagonistas, em um composto de casca de eucalipto nãoesterilizado, e de 10-15 dias, no composto esterilizado, para reduzir a mela de estacas em eucalipto, causada por um isolado binucleado de Rhizoctonia sp. (Kunieda-de-Alonso, 1997).

A aparente inconsistência dos efeitos dos compostos de casca de eucalipto na supressão de Rhizoctonia spp. já foi observada para outros tipos de compostos, como casca de coníferas e folhosas, lixo urbano ou doméstico (Hoitink \&
Fahy, 1986). Quaisquer que sejam as causas da inconsistência dos resultados obtidos com os diferentes compostos de casca empregados nos presentes ensaios, é fundamental conhecer com exatidão as características físico-químicas e biológicas de cada composto, para determinar posteriormente que fatores podem determinar essa supressividade (Ceuster \& Hoitink, 1999).

Em todos os ensaios em condições controladas e microparcelas, a incorporação de folhas de eucalipto parcialmente decompostas estimulou a atividade saprofítica de Rhizoctonia spp., sendo esse estímulo mais evidente em solos com baixas densidades de inóculo. O estado de decomposição da matéria orgânica é, talvez, o fator mais importante na atividade saprofítica e em doenças causadas por Rhizoctonia spp. Materiais orgânicos frescos geralmente estimulam o crescimento micelial, enquanto os parcial ou totalmente decompostos, freqüentemente, reduzem (Van Bruggen et al., 1996). Os resultados obtidos são importantes sob o ponto de vista do manejo do jardim clonal e indicam a necessidade de se eliminarem os restos de podas de limpeza, ou de favorecer sua rápida decomposição, especialmente em épocas do ano que apresentem maior risco para o desenvolvimento de epidemias severas.

Os resultados obtidos indicam que os antagonistas, especialmente T. inhamatum (UFV-2 e UFV-3), e alguns tipos de compostos de casca de eucalipto apresentam potencial para serem utilizados na supressão de Rhizoctonia spp. em solos de jardim clonal de eucalipto. No entanto, será necessário conhecer melhor os fatores ecológicos e tecnológicos que permitam melhorar a eficiência dos compostos e a consistência nos resultados na supressão de Rhizoctonia spp., em condições de campo, compatíveis com aspectos operacionais e econômicos das empresas.

\section{AGRADECIMENTO}

Ao CNPq pelas bolsas concedidas e a FAPEMIG pelo aporte de recursos.

\section{REFERÊNCIAS BIBLIOGRÁFICAS}

ALFENAS, A.C., SILVEIRA, S.F. \& SANFUENTES, E. Current status and control strategies of diseases associated to clonal propagation of Eucalyptus in Brazil. In: IUFRO CONFERENCE ON SILVICULTURE AND IMPROVEMENT OF Eucalyptus. Proceedings... Colombo: EMBRAPA. Centro Nacional de Pesquisas Florestais, Colombo. 1997. pp.106-111.

ANDRADE, A.M. Influência da casca de Eucalyptus grandis W. Hill ex Maiden no rendimento e qualidade de carvão vegetal. (Dissertação Mestrado) Universidade Federal de Viçosa, 1989.

CEUSTER, T.J.J. \& HOITINK, H.A.J. Using compost to control plant diseases. Biocycle 40:61-64. 1999.

CHUNG, Y.R., HOITINK, H.A.J., DICK, W.A. \& HERR, L.J. Effects of organic matter, decomposition level, and cellulose amendement on the inoculum potencial of Rhizoctonia solani in hardwood bark media. Phytopathology 78:836-840. 1988.

EASTBURN, D.M. \& BUTLER, E.E. Effects of soil moisture and temperature on the saprophytic ability of Trichoderma 
Supressão da atividade saprofítica de Rhizoctonia spp. em solos ...

harzianum. Mycologia 83:257-263. 1991.

ELAD, Y., CHET, I. \& KATAN, J. Trichoderma harzianum: A biocontrol agent effective against Sclerotium rolfsii and Rhizoctonia solani. Phytopathology 70:119-121. 1980.

HARDY, G.E., SIVASITHAMPARAM, K. Antagonism of fungi and actinomycetes isolated from composted eucalyptus bark to Phytophthora drechsleri in steamed and non-steamed composted eucalyptus bark-amended medium. Soil Biology Biochemistry 27:243-246. 1995.

HOITINK, H.A.J. Composted bark, a lightweight growth medium. Plant Disease 64:142-147. 1980.

HOITINK, H.A.J. \& FAHY, P.C. Basis for the control of soilborne plant pathogens with composts. Annual Review of Phytopathology 24:93-114. 1986.

HUANG, J.W. \& KULHMAN, E.G. Formulation of soil amendment to control damping-off of slash pine seedlings. Phytopathology 81:163-170. 1991.

KNUDSEN, G.R. \& BIN, L. Effects of temperature, soil moisture, and wheat bran on growth of Trichoderma harzianum from alginate pellets. Phytopathology 80:724-727. 1990.

KO, W. \& HORA, F. A selective medium for the quantitative determination of Rhizoctonia solani in soil. Phytopathology 61:707-710. 1971.

KUNIEDA-DE-ALONSO, S. Trichoderma longibranchiatum e $T$. inhamatum como agentes de controle da mela de estacas de eucalipto, causada por Rhizoctonia. (Dissertação de Mestrado) Universidade Federal de Viçosa, 1997.

KUTER, G.A., HOITINK, H.A.J. \& CHEN, W. Effects of municipal sludge compost curing time on suppression of Pythium and Rhizoctonia spp. diseases of ornamental plants. Plant Disease 72:751-756. 1988.

KWOK, O.C.H., FAHY, P.C., HOITINK, H.A.J. \& KUTER, G.A. Interactions between bacteria and Trichoderma hamatum in suppression of Rhizoctonia spp. damping-off in bark compost media. Phytopathology 77:1206-1212. 1987.

LEWIS, J.A., LUMDSEN, R.D. \& LOCKE, J.C. Biocontrol of damping-off diseases caused by Rhizoctonia solani and Pythium ultimun with alginate prills of Gliocladium virens, Trichoderma hamatum and various food bases. Biocontrol Science and Technology 6:163-173. 1996.

LEWIS, J.A. \& PAPAVIZAS, G.C. Application of Trichoderma and Gliocladium in alginate pellets for control of Rhizoctonia damping-off. Plant Pathology 36:438-446. 1987.

LEWIS, J.A., PAPAVIZAS, G.C. \& LUMDSEN, R.D. A new formulation system for the application of biocontrol fungi to soil. Biocontrol Science 7:59-60. 1991.

PAPAVIZAS, G.C. Trichoderma and Gliocladium: biology, ecology, and potential for biocontrol. Annual Review of Phytopathology 23:23-54. 1985 .

ROSS, R.E., KEINATH, A.P. \& CUBETA, M.A. Biological control of wistertem on cabbage using binucleate Rhizoctonia spp. Crop Protection 17:99-104. 1998.

SANFUENTES, E. \& ALFENAS, A.C. Evaluation of saprophytic capacity and pathogenicity of Rhizoctonia spp. in the clonal propagation system of Eucalyptus. In: INTERNATIONAL CONGRESS OF PLANT PATHOLOGY, 7. Edimbourgh, Scotland, 1998. Abstract 3.7.37.

SILVEIRA, S.F., ALFENAS, A.C., FERREIRA, F.A. \& SUTTON, J.C. Characterization of Rhizoctonia species associated with foliar necrosis and leaf scorch of clonally-propagated Eucalyptus in Brazil. European Journal of Plant Pathology 106:27-36. 2000.

SNEH, B., BURPEE, L. \& OGOSHI, A. Identification of Rhizoctonia species. St. Paul: APS Press, 1991.

STEINMETZ, J. \& SCHÖNBECK, F. Conifer bark as growth medium and carrier for Trichoderma harzianum and Gliocladium roseum to control Pythium ultimum on pea. Journal of Plant Disease and Protection 101:200-211. 1994.

TUITER, G., SZSCZECH, M. \& BOLLEN, G.J. Suppression of Rhizoctonia solani in potting mixtures amended with compost made from organic household waste. Phytopathology 88:764773. 1988.

VAN BRUGGEN, A.H.C., GRÜNWALD, N.J. \& BOLDA, M. Cultural methods and soil nutrient status in low and high input agricultural systems, as they affect Rhizoctonia species. In: Sneh, B., Jabahi-Hare, S., Neate, S. \& Dijst, G (Eds.) Rhizoctonia species: taxonomy, molecular biology, ecology, pathology, and disease control. Dordrecht, Netherlands: Kluwer Academic Publishers, 1996. pp.407-421.

WEINHOLD, A.R. Population of Rhizoctonia solani in agricultural soils determined by a screening procedure. Phytopathology 67:566-569. 1977.

YUEN, G.Y., MISCHELL, L.C. \& GIESLER, L.J. Biological control of Rhizoctonia solani on tall fescue using fungal antagonist. Plant Disease 78:118-123. 1994. 